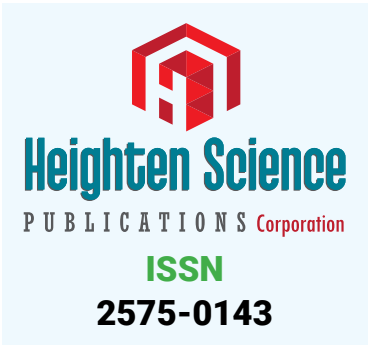

*Address for Correspondence: Nilda EspinolaZavaleta, Nuclear Cardiology, National Institute of Cardiology, Ignacio Chavez, Juan Badiano $\mathrm{N}^{\circ}$ 1, Colonia Section XVI, Tlalpan Zip Code - 14080 Mexico City, Mexico,

Email: niesza2001@hotmail.com

Submitted: 03 June 2019

Approved: 19 June 2019

Published: 20 June 2019

Copyright: (c) 2019 Rodriguez-Zuñiga CJ, et al. This is an open access article distributed under the Creative Commons Attribution License, which permits unrestricted use, distribution, and reproduction in any medium, provided the original work is properly cited

D) Check for updates

\section{Acute viral myocarditis due to Influenza H3N2 infection resembling an acute coronary syndrome: $A$ case report}

\author{
Carlos Jesus Rodriguez-Zuñiga ${ }^{1}$, Leonel Martínez-Ramírez ${ }^{1,2}$, \\ Carlos Alberto Guizar-Sanchez ${ }^{1,3}$, Mauricio Quetzal Trejo- \\ Mondragon $^{1}$ and Nilda Espinola-Zavaleta ${ }^{{ }^{*}}$ \\ ${ }^{1}$ Intensive Care Unit, South-Central Hospital, Mexican Oil Company, Mexico City, Mexico \\ ${ }^{2} \mathrm{Head}$ of the Cardiology Department, South-Central Hospital, Mexican Oil Company, Mexico \\ City, Mexico \\ ${ }^{3}$ Nuclear Cardiology Department, National Institute of Cardiology, Ignacio Chavez, Mexico City, \\ Mexico
}

\section{Case Presentation}

A 16-year-old man with history of two weeks-flu like symptoms with intermittent fever. He came to the emergency department with 2 hours-chest pain that radiates to the back and upper extremities. At the admission he was hemodynamically stable with normal blood pressure The ECG showed sinus rhythm and ST segment elevation of 0.5 $\mathrm{mV}$ in all leads (Figure 1A). The cardiac enzymes were elevated (Troponin $12.19 \mathrm{ng} /$ mLland creatine kinase-MB fraction 63.25 U/L). He was admitted to the Intensive Care Unit and later transferred to our medical unit to continue with study protocol. The transthoracic echocardiogram (Figure 1B) reported normal left ventricular systolic function with left ventricular ejection fraction (LVEF) 68\%, global longitudinal strain $-18 \%$, TAPSE $30 \mathrm{~mm}$, and normal systolic pulmonary artery pressure (30 $\mathrm{mmHg}$ ).

During hospitalization a complete serologic analysis demonstrated positive PCR and genetic study for Influenza H3N2. Other causes of fever (bacterial infection, inflammation of the lining of your joints, malignant tumor, some medications and immunizations) were discarded.

The cardiac magnetic resonance imaging showed myocarditis with late gadolinium enhancement in the infero-lateral and inferior walls, without pericardial involvement, left ventricular global hipokinesia with LVEF of 53\% and no valvular lesions (Figure 1C,D). Medical treatment was started with clinical improvement after 10 days. Also, the cardiac enzymes normalized (Troponin $0.37 \mathrm{ng} / \mathrm{mL}$ and creatine kinase-MB fraction 12.5 U/L.) During the 7 months follow-up he is in NYHA functional class I.

This is a case of acute myocarditis caused by H3N2 Influenza virus. Viruses are the more frequent cause of infectious myocarditis, although the most frequent of them is parvovirus B19, therefore an acute myocarditis due to Influenza virus is uncommon [1]. This etiology can mimic an acute coronary syndrome with preserved left ventricular systolic function. The majority of these patients (such as ours) have good short-term prognosis. 


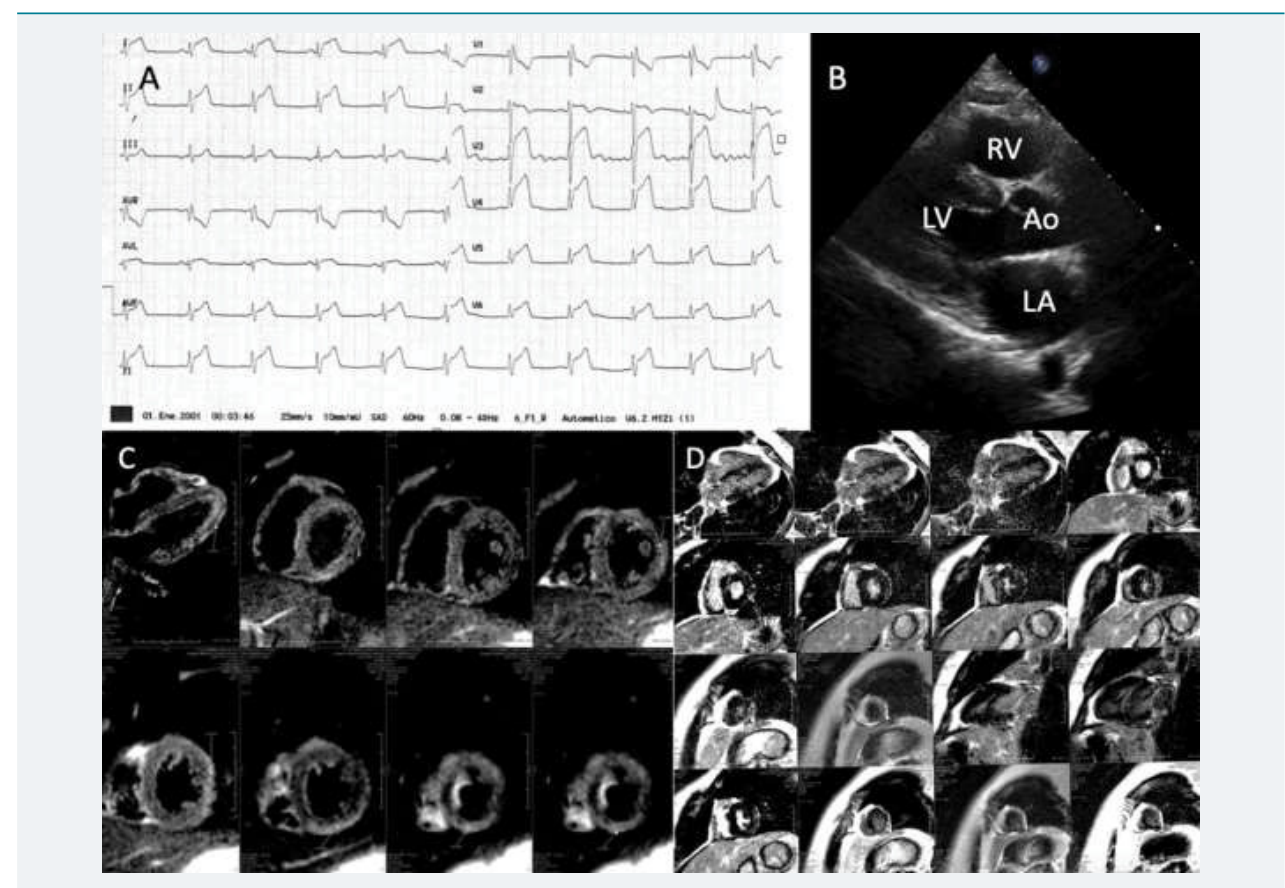

Figure 1: Acute viral myocarditis. A: Emergency department ECG that showed sinus rhythm and ST segment elevation of $0.5 \mathrm{mV}$ in all leads. B: Transthoracic echocardiogram with normal diameters and systolic wall thickness. $\mathrm{C}, \mathrm{D}$ : Cardiac magnetic resonance with late gadolinium enhancement in the left ventricular infero-lateral and inferior walls, suggestive of myocarditis.

\section{References}

1. Sandeep S, Liu P, Cooper Jr L. Myocarditis. Lancet. 2012; 379: 738-747. Ref.: http://bit.ly/2WTHXNx 